\title{
A Study of Diffusion Phenomenon in Friction Stir Lap Welding Joints for Low Carbon Steel C10 to Aluminum Alloy AA1100- H112
}

\author{
Muna Khethier Abbass \\ Dept. of Production Engineering and Metallurgy, \\ University of Technology, Baghdad-Iraq
}

Received: 18-April-2018 http://doi.org/10.29194/NJES.21040479

\author{
Kareem Mohsen Raheef \\ College of Engineering, Almustansria University, \\ Baghdad-Iraq. \\ kareem.raheef@yahoo.com
}

Revised: 28-May-2018 Accepted: 18-Sep.-2018

\begin{abstract}
:
In this study the friction stir lap welding was carried out by a new technique (diffusion bonding phenomenon) between (AA1100 and low carbon steel $\mathrm{C} 10$ sheets of $3 \mathrm{~mm}$ and $1 \mathrm{~mm}$ thickness respectively. These alloys have difference ranges in melting temperature and other physical properties. Different parameters were used: tool rotation speeds $(630,1250) \mathrm{rpm}$, travel speeds $(80,32) \mathrm{mm} / \mathrm{min}$. and pin length $(2.8,3) \mathrm{mm}$ using cylindrical threaded pin. Many tests and inspections were performed such as tensile shear test and X-Ray diffraction tests. Microhardness and microstructure observations were conducted by using optical and SEM. The above tests were used to evaluate the weld quality and joint efficiency under different welding parameters. Best result for FSLW by diffusion phenomenon appear in (low carbon steelC10 / AA1100-H112) joint at $1250 \mathrm{rpm}$ in $32 \mathrm{~mm} / \mathrm{min}$. with $2.8 \mathrm{~mm}$ pin length and the maximum tensile shear strength was (3.9)KN.It was found that the highest micro hardness was $(138 \mathrm{HV})$ at the interface between the low carbon steel and AA1100.
\end{abstract}

\section{1-Introduction}

Friction stir welding(FSW) is a solid state welding technology that can be used to connect not only aluminum alloys that are weldable by conventional methods but also high-resistance aluminum and some other hard- alloys that are difficult to weld using traditional fusion welding processes [1].

The friction stir welding was developed in England by The Welding Institute (TWI) in 1991. High-quality weld can be created by this process with e. g. a milling machine because using same movement conditions but the tool is different [2].

There are several dependent and independent operating variables that could impact the FSW process. According to literature, field of temperature, heating and cooling rate, applied torque, axial force are the key independent variables. In contrast, speed of welding, tool downward pressure, rotational velocity, tool geometry and inclination angle are the chief independent variables [3].

The majority of FSW studies have been based on butt joint geometry. Lap joint configuration which shown in "Figure 1" is also widely used in conventional welding and friction stir lap welding (FSLW) [4]. Lap joint and its parameters which shown in "Fig. 1" usually used in finishing process of parts in aerospace, air craft and automotive manufacturing. In recent years, FSW has been the most suited for aluminum alloys lap joints [5]. H. Bisadi et al. [6] studied the microstructure and mechanical properties in certain FSW process parameters (rotational and welding speed) for lap joint welding. The material used was 5083 aluminum alloy, $2.5 \mathrm{~mm}$ thick and the parameters applied were $600,825,1115,1550$ $\mathrm{rpm}$ rotational speeds and $32,60 \mathrm{~mm} / \mathrm{min}$ welding speeds, He found that a superior weld joint is obtained at lower rotational and welding speeds. In this case, it is recommended to use higher welding speeds to increase the thermal gradient at the weld zone. The results showed that reduced heat transfer and not enough stirred area are the cause for the joint defects that occurred at 600 rpm rotational speed.

Muna K. Abbass et al. [7] investigated two welding processes: friction stir welding (FSW) and tungsten inert gas (TIG). For TIG, $4 \mathrm{~mm}$ thick $\mathrm{Al}$ 6061-T6 and filler metal of Al-Mg alloy were used and FSW was employed through automatic milling machine at various bed speeds $(25,50,80$, 100 and $125 \mathrm{~mm} / \mathrm{min}$ ) and tool rotational speeds $(630,800,1000,1250$ and1600 rpm). The results of the investigations showed:

For FSW the best results were obtained at $1250 \mathrm{rpm}$ with $50 \mathrm{~mm} / \mathrm{min}$ and at $800 \mathrm{rpm}$ with $125 \mathrm{~mm} / \mathrm{min}$. Using these parameters for FSW, the tensile test and joint efficiency results were superior to those of TIG joint (79\% as opposed to $57 \%)$.

FSW joints had superior results of tensile test compared to TIG joints because of the fine equiaxed grains and strengthening precipitates that develop during the FSW process.

Sadiq Aziz et al. [8] applied FSW to obtain butt joints of AA5083 and AA6061 aluminum 
alloy plates (3 $\mathrm{mm}$ thick) to electro-galvanized steel. The conclusions are:- The single-pass FSW attempt of the three dissimilar materials was successful. The highest joint efficiency $(73 \%)$ was obtained at $900 \mathrm{rpm}$ rotational speed, $20 \mathrm{~mm} / \mathrm{min}$ welding speed and diffusion technique.

Muna K. Abbass et al. [9] applied FSW for joining AA2024-T3 and AA7075-T73 dissimilar aluminum alloys of $3 \mathrm{~mm}$ thickness and they concluded that when the welding speed was increased the tensile strength of the welded joints is increased.Grain refinement and precipitates increase the microhardness in SZ as opposed to the values obtained through TMAZ and HAZ.

Esther T. Akinlabi et al. [10] studied the influence of the rotational speed on the integrity of the weld joint. Lap joints obtained through
FSW, 1050 aluminum alloy, $3 \mathrm{~mm}$ thick plates, $1200 \mathrm{rpm}$ - $2000 \mathrm{rpm}$ rotational speeds, 150 $\mathrm{mm} / \mathrm{min}$ traverse speed (constant). The results showed that the macrostructure revealed a basin shape in the nugget, due to high deformation and frictional heat occurring at upper surface level. The microstructure showed fine and equiaxed grains with smaller grain size than the original material in the stirred zone. Dynamic recrystallization and plastic deformation produced the transformed stirred zone.

The aim of this work is to study the diffusion phenomenon on the microstructure and the mechanical properties of dissimilar Friction Stir Lap Welding (FSLW) joints for aluminum alloys (AA1100-H112) and galvanized low carbon steel C10.

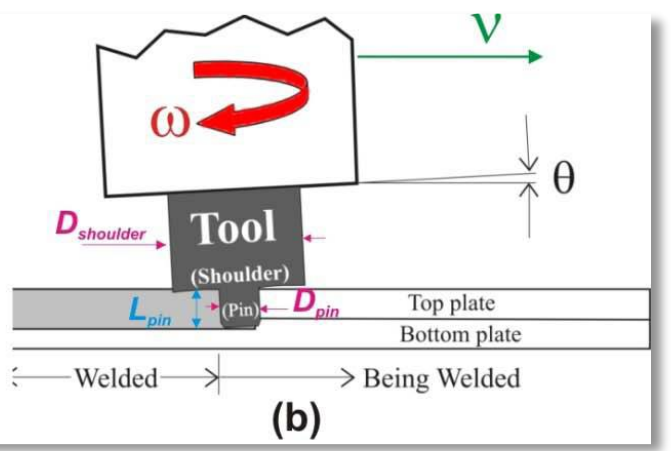

Figure 1: Schematic illustration: (a) FSLW process and (b) various FSLW parameters [4].

\section{Experimental Work}

\subsection{Materials}

Commercially aluminum alloys (AA1100H112 and Galvanized mild steel C-10) plates of thickness $3 \mathrm{~mm}$ and $1 \mathrm{~mm}$ respectively were used and prepared to be joined by FSLW diffusion bonding phenomenon. The plates dimension were $(200 \times 100) \mathrm{mm}^{2}$. A fixture and back plate were especially made to fix and support the plates to be welded on the milling machine table. The chemical composition of the two alloys were shown in "Table 1 and 2 ".

Table 1: Chemical Composition for the alloy AA1100H112HH112

\begin{tabular}{|c|c|c|c|c|c|c|c|c|c|c|c|}
\hline $\begin{array}{c}\text { Element } \\
\text { wt. \% }\end{array}$ & $\mathrm{Si}+\mathrm{Fe}$ & $\mathrm{Cu}$ & $\mathrm{Mn}$ & $\mathrm{Mg}$ & $\mathrm{Cr}$ & $\mathrm{Ni}$ & $\mathrm{Zn}$ & $\mathrm{Ti}$ & \multicolumn{2}{|c|}{$\begin{array}{c}\text { Others } \\
\text { Each Total }\end{array}$} & $\overline{\mathrm{Al}}$ \\
\hline $\begin{array}{c}\text { Nominal } \\
\text { (value) }\end{array}$ & $\begin{array}{l}0.95 \\
\text { Max }\end{array}$ & $\begin{array}{c}0.2 \\
\max \end{array}$ & $\begin{array}{l}0.05 \\
\operatorname{Max}\end{array}$ & - & - & - & $\begin{array}{c}0.1 \\
\max \end{array}$ & - & 0.05 & 0.15 & Bal. \\
\hline Measured & 0.746 & 0.154 & 0.003 & 0.0019 & 0.006 & 0.003 & Nil & Nil & 0.007 & & Bal. \\
\hline
\end{tabular}

Table 2 Chemical composition for the low carbon steel-C10

\begin{tabular}{|c|c|c|c|c|c|c|c|c|c|c|}
\hline Element wt.\% & $\mathbf{C \%}$ & $\mathbf{S i} \%$ & $\mathbf{C u \%}$ & $\mathbf{M n \%}$ & $\mathbf{P \%}$ & $\mathbf{S \%}$ & $\mathbf{C r \%}$ & $\mathbf{M o \%}$ & $\mathbf{N i} \%$ & $\mathbf{T i} \%$ \\
\hline Nominal (value) & 0.0476 & 0.0175 & 0.0319 & 0.199 & 0.0130 & $<0.001$ & 0.0153 & 0.0038 & 0.0104 & $<0.0005$ \\
\hline Element wt.\% & $\mathbf{A l \%}$ & $\mathbf{A s \%}$ & $\mathbf{B \%}$ & $\mathbf{C o \%}$ & $\mathbf{C a \%}$ & $\mathbf{N b \%}$ & $\mathbf{S n \%}$ & $\mathbf{V \%}$ & $\mathbf{Z r \%}$ & $\mathbf{F e \%}$ \\
\hline Nominal (value) & 0.0368 & 0.0032 & 0.0009 & 0.0059 & $<0.0005$ & $<0.001$ & $<0.001$ & 0.0018 & 0.0034 & Bal. \\
\hline
\end{tabular}

\subsection{FSLW process procedure}

FSLW operation was conducted out to produce lap welding joints for dissimilar aluminum alloys (AA1100-H112 to low carbon steel $\mathrm{C} 10$ ) by new diffusion phenomenon. After experimental setup of milling machine, the specimens were mounted over the back plate then supported firmly by special the clamps and bolts with the aid of fixtures. After that the FSW tool pin was rotated clockwise at the desired speed. Suitable selection for rotational speeds and travel 
speeds which are $(630,1250) \mathrm{rpm}$ and $(32,80)$ $\mathrm{mm} / \mathrm{min}$ respectively.

The high speed steel tool was used as shown in Fig. 2, the diameter of the shoulder is $16 \mathrm{~mm}$, the pin diameter equal to $6 \mathrm{~mm}$ threaded by $(\mathrm{M} 6 \times 1)$ and its length equal to $2.8 \mathrm{~mm}$ and $3 \mathrm{~mm}$.
The Friction stir lap welding (FSLW) method was conducted out at variables welding parameters: Inclined angle $\left(2^{\circ}\right)$, penetration depth of shoulder surface $(0.1) \mathrm{mm}$, pin length $(2.8,3) \mathrm{mm}$ and dwell time (30sec) stay fixed (Fig.3).
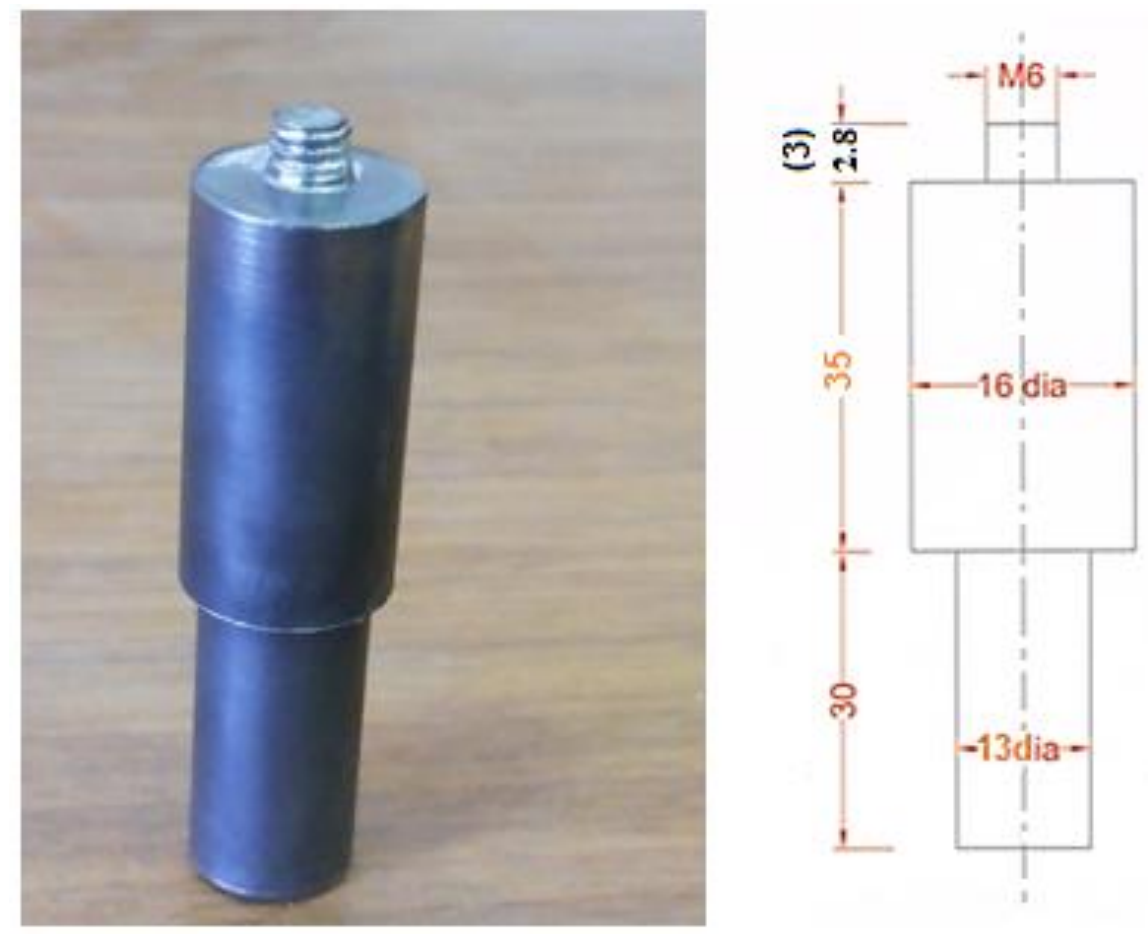

Figure 2: Specification of the Tool: (a) Tool picture (CY) (b) Tool dimensions

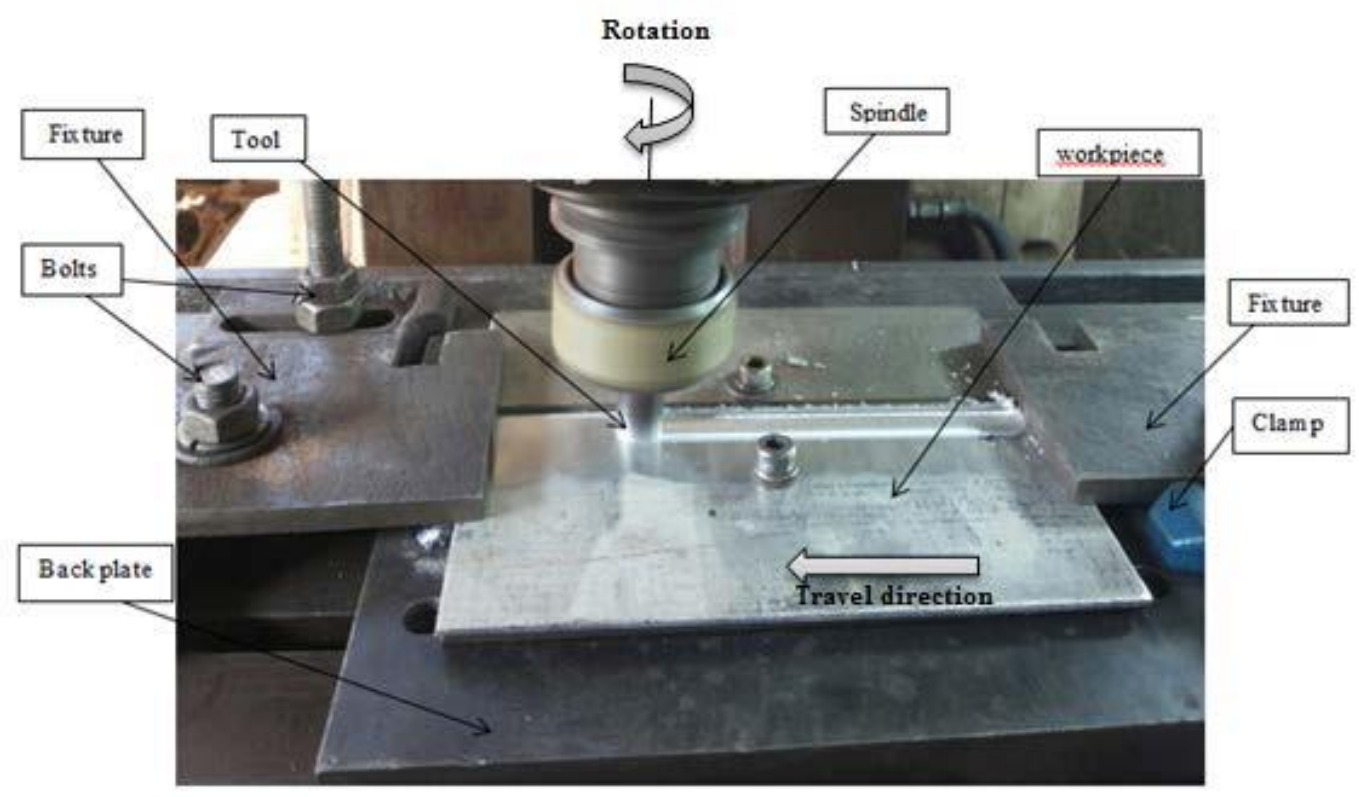

Figure 3: Shows the Welding tool, work piece clamp \& fixture on the milling machine bed

\section{Results and Discussions}

\subsection{Tensile shear Force test}

Tensile-shear test of lap weld has been used to evaluate the shear strength of FSLW joint. Table 3 explain the welding parameters and joint 
efficiency for the two specimens welded by diffusion bonding phenomenon.

The friction stir Lap welding by diffusion bonding phenomenon for (AA1100 to low carbon steel) was conducted in two different conditions, the first case was under $630 \mathrm{rpm} \& 80 \mathrm{~mm} / \mathrm{min}$. \& pin length of $3 \mathrm{~mm}$,during the test the maximum shear force record $0.75 \mathrm{KN}$. See figure (4), and this value is very low due to low rotational speed also high travel speed this parameters lead to low heat generation and insufficient time for stirring and diffusion the heat flow from upper sheet(Al) to lower sheet(steel).While the second case ( $1250 \mathrm{rpm} \& 32 \mathrm{~mm} / \mathrm{min})$, and the pin length $2.8 \mathrm{~mm}$.It is clear from Figure (5), the Shear force increased to $3.9 \mathrm{KN}$ and this result is an agreement with many researchers [11]. The weld strength $(\sigma$ Lap) which represent the maximum load $(\mathrm{N})$ over the specimen width ( $\mathrm{mm})$ [7]. This value was $460 \mathrm{~N} / \mathrm{mm}$, so it is considered a good result due to the convenient conditions for heat generation and enough stir time. The mechanism of this joint looks like a diffusion bond due to sufficient applied (axial force and heat input) which lead to diffusion bonding mechanism.

\subsection{Microstructure test}

Figure(6) shows the microstructure of dissimilar FSLW joint ( low carbon steel to AA1100) by diffusion phenomenon at the suitable Welding conditions of $1250 \mathrm{rpm} /$ $32 \mathrm{~mm} / \mathrm{min}$ and pin length of $2.8 \mathrm{~mm}$. The presence of sufficient heat input and axial force, which make a phenomenon look like to diffusion bonding between AA1100-H112 and low carbon steel C10.

\subsection{Hardness Tests}

Fig.(6) shows the Microhardness distribution in the cross section of the dissimilar FSLW joint ( Mild steel to AA1100) by diffusion technique at the suitable Welding conditions of $1250 \mathrm{rpm}$, $32 \mathrm{~mm} / \mathrm{min}$ and pin length of $2.8 \mathrm{~mm}$. Hardness varied between $145 \mathrm{HV}$ and $32 \mathrm{HV}$. The minimum \& maximum hardness was found in the base metal of (AA1100) and low carbon steel base metal which were $32 \mathrm{HV} \& 145 \mathrm{HV}$ respectively. From low carbon steel base metal the hardness begin to decrease slightly through the interface zone of both the advancing and retreating side. The hardness of the interface here have medium value between other weld areas 132HV.This may be cause due to the formation of very fine recrystallized grains at the interface. Also The applied parameters generate enough heat input to the stir zone that caused diffusion bonding phenomenon between the elements of AA1100 and low carbon steel sheets at the interface surface.

\subsection{XRD analysis results}

Fig. (7) explains the XRD result for diffusion bonding for steel/AA1100 joint, some phases were appeared such as, $\mathrm{FeAl}, \mathrm{FeAl}_{3}$ and $\mathrm{AlFe}_{3}$ phases..

Table (3): FSLW diffusion bonding parameters \& joint efficiency for Dissimilar alloys

\begin{tabular}{|c|c|c|c|c|c|c|}
\hline No. & $\begin{array}{c}\text { Rotational } \\
\text { speed } \\
\text { rpm }\end{array}$ & $\begin{array}{c}\text { Feed speed } \\
\text { mm/min. }\end{array}$ & $\begin{array}{c}\text { Max.Load } \\
\text { KN }\end{array}$ & $\begin{array}{c}\text { Pin } \\
\text { length } \\
\text { mm }\end{array}$ & $\begin{array}{c}\text { Maximum } \\
\text { oLap N/mm }\end{array}$ & $\begin{array}{c}\text { efficiency } \\
\%\end{array}$ \\
\hline F1 & 630 & 80 & 0.75 & 3 & 38 & 14 \\
\hline F2 & 1250 & 32 & 3.9 & 2.8 & 260 & 73.6 \\
\hline
\end{tabular}

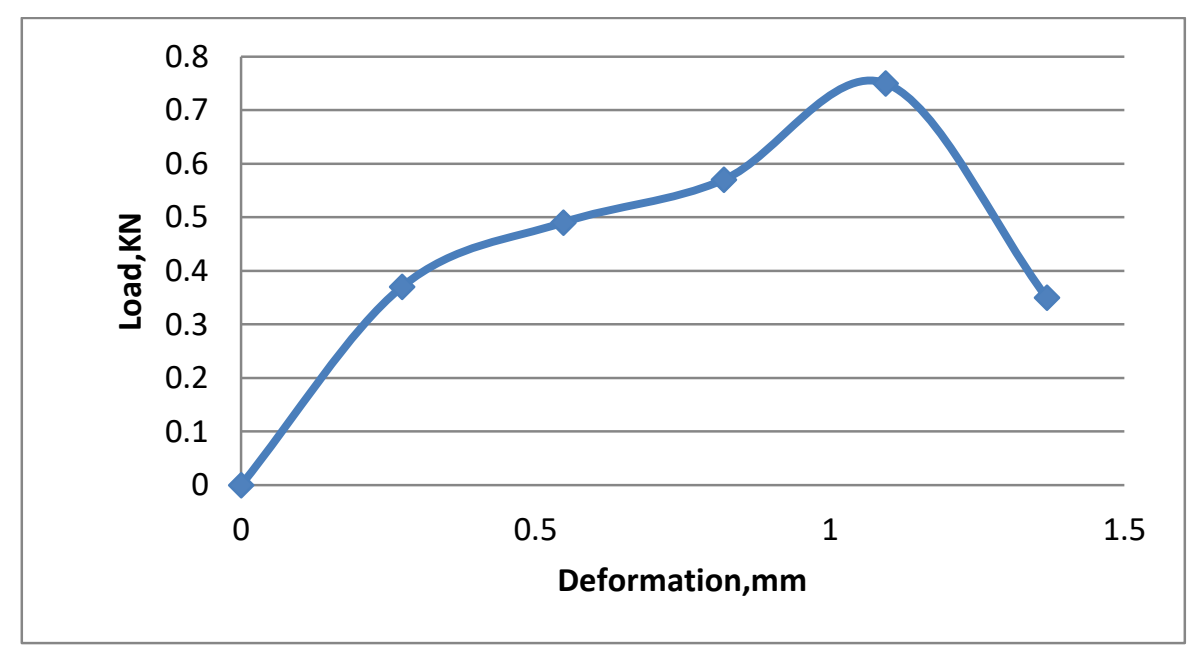

Figure (4): Load-Deformation relationship for AA1100 to low carbon steel under $630 \mathrm{rpm} \& 80 \mathrm{~mm} / \mathrm{min}$, pin length $3 \mathrm{~mm}$. 


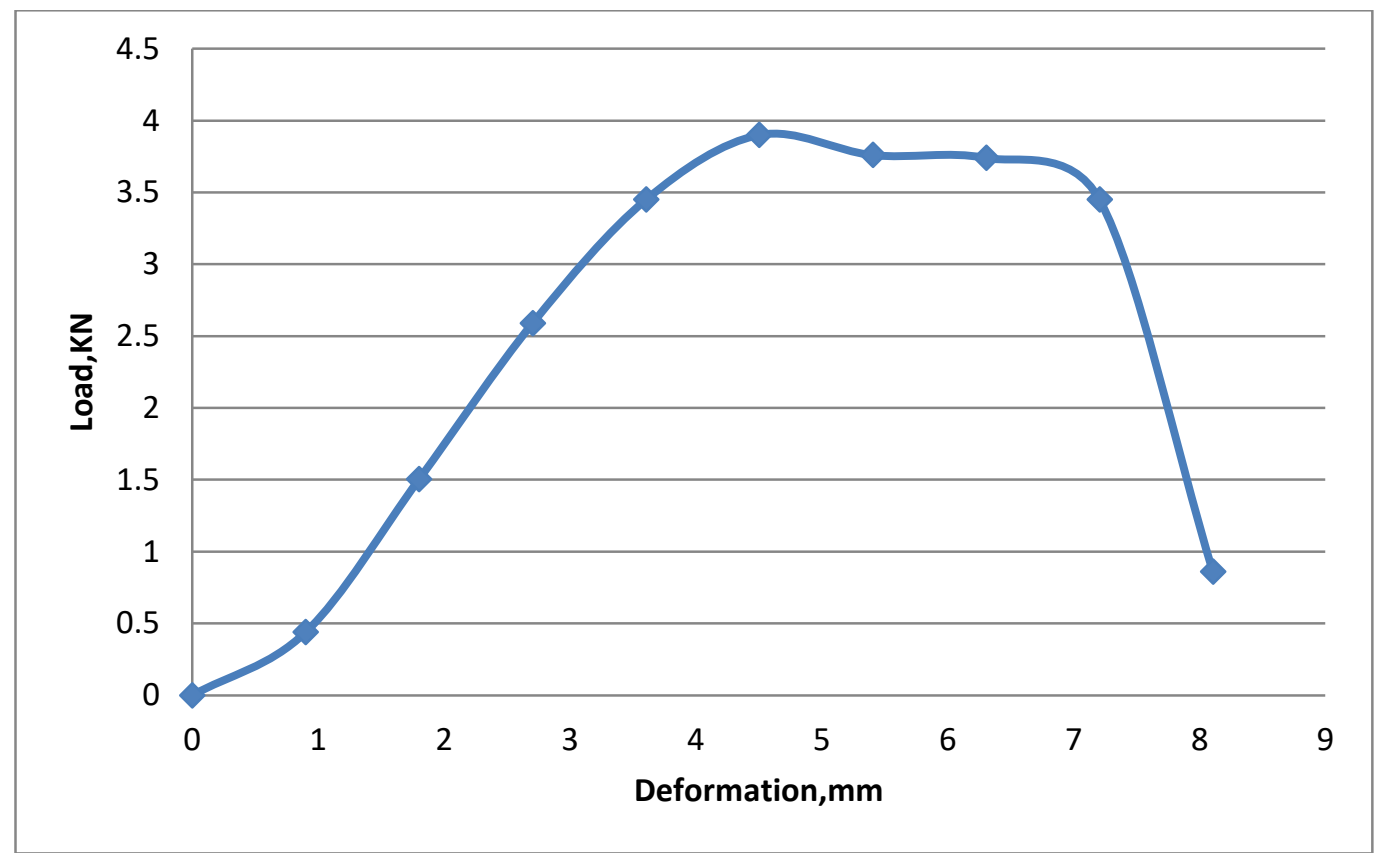

Figure (5): Load-Deformation relationship for AA1100 to low carbon steel under $1250 \mathrm{rpm} \& 32 \mathrm{~mm} / \mathrm{min}$, pin length $2.8 \mathrm{~mm}$.

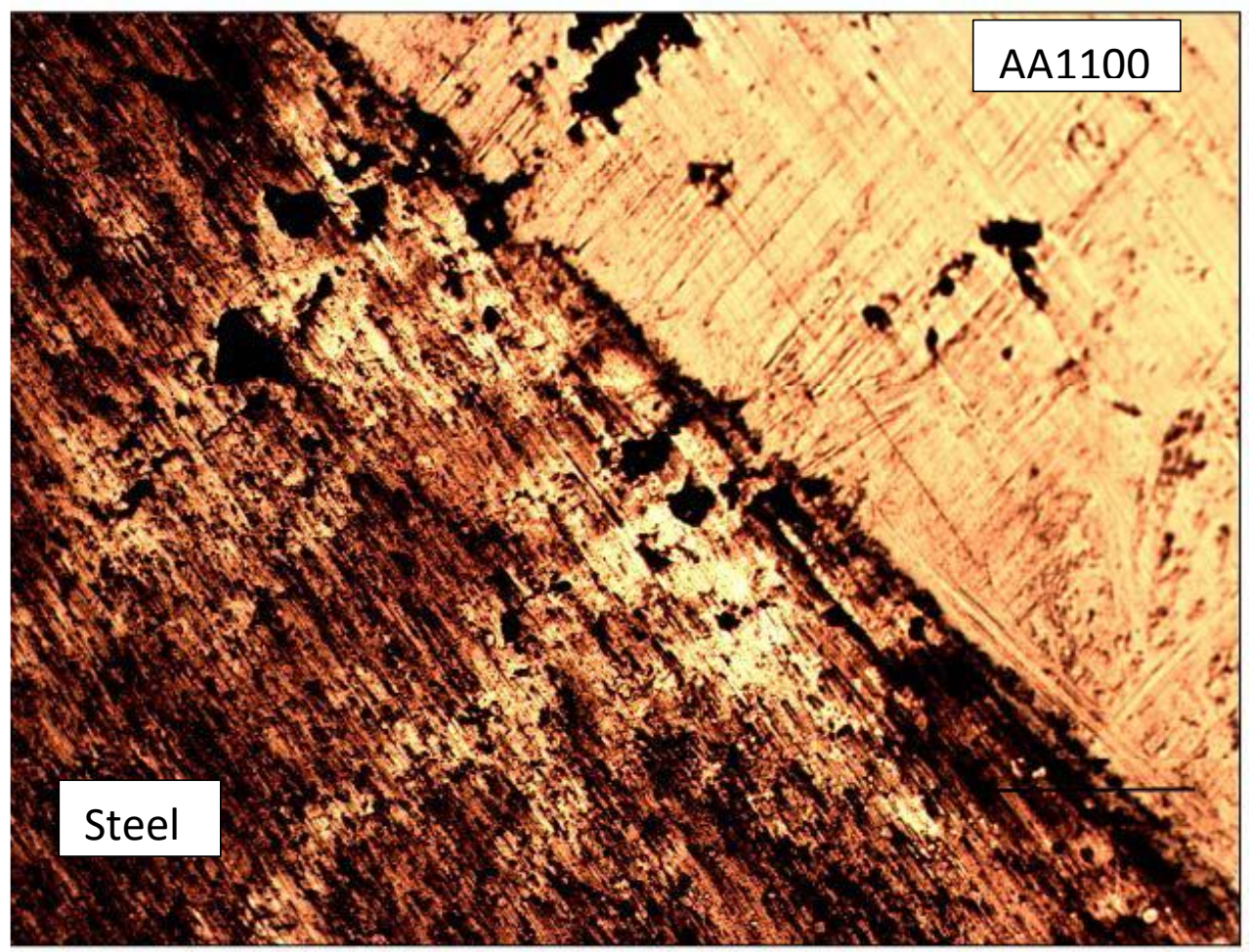

Figure (6): Microstructure the dissimilar FSLW joint (Mild steel to AA1100) by diffusion phenomenon at the suitable Welding conditions of $1250 \mathrm{rpm}, 32 \mathrm{~mm} / \mathrm{min}$ and pin length of $2.8 \mathrm{~mm}$. 

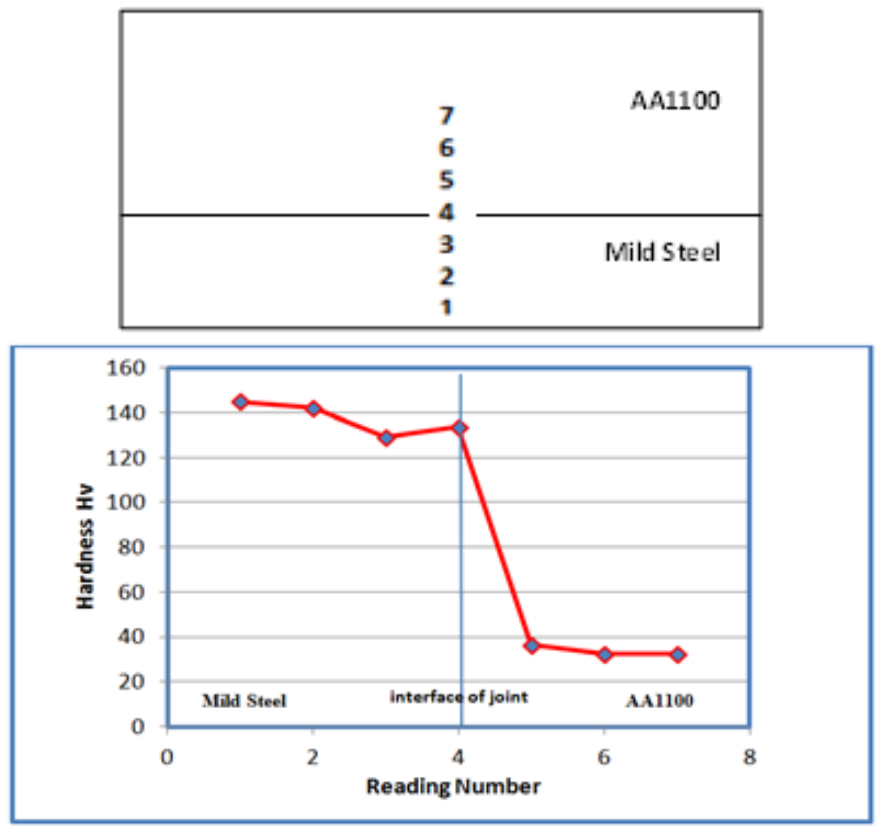

Figure (7): Microhardness distribution in the cross section of the dissimilar FSLW joint (Mild steel to AA1100) by diffusion phenomenon at the suitable Welding conditions of $1250 \mathrm{rpm}, 32 \mathrm{~mm} / \mathrm{min}$ and pin length of $2.8 \mathrm{~mm}$.

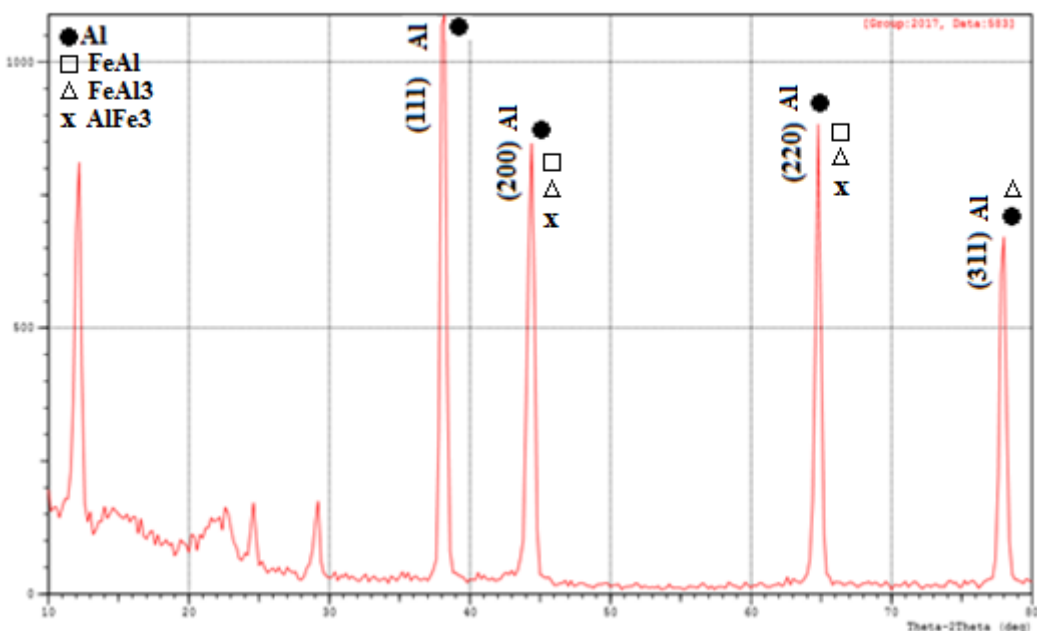

Figure (8): Represent XRD result for diffusion phenomenon bonding for steel/AA1100 at $1250 \mathrm{rpm} \&$ $32 \mathrm{~mm} / \mathrm{min}$ and pin length $2.8 \mathrm{~mm}$.

\section{Conclusion}

1. Friction stir lap welding (FSLW) diffusion bonding phenomenon for dissimilar joint (AA1100 and low carbon steel C10) was successfully performed and gave good lap joints efficiency $(73.6 \%)$.

2 . The best welding conditions or parameters in FSLW process were tool rotation speed (1250rpm), Travel speed $(32 \mathrm{~mm} / \mathrm{min}$.) with using pin length of $2.8 \mathrm{~mm}$ with cylindrical threaded pin profile.

3 . The higher hardness value were $(145 \mathrm{HV})$ at low carbon steel side, while at the interface it was $138 \mathrm{HV}$ and it drops toward the base metals for AA1100 side.

\section{References}

[1] Ákos Meilinger, Imre Török. (2013). "The Importance of Friction Stir Welding Tool", Production Processes and Systems, vol. 6, No. 1, pp. 25-34.

[2] Florian A. Besler, Paul Schindele, Richard J. Grant, Michael J.R. Stegmüller. (2016).

"Friction crush welding of aluminum, copper and steel sheet metals with flanged edges", Journal of Materials Processing Technology 234, 72-83.

[3] Shamzin Yazdanian. (2012). "Metallurgical Studies of Friction Stir Lap Welding", PhD thesis, Auckland University.

[4] Aleem Pasha M.D.,Ravinder Reddy P. Laxminarayana P.and Ishtiaq Ahmad Khan.( 
2014). "Influence Of Process And Tool Parameters On Friction Stir Welding-Over View", International Journal of Applied Engineering and Technology, Vol. 4 (3) JulySeptember, pp.54-69

[5] Z.W. Chen, S. Yazdanian. (December 2012). "Friction Stir Lap Welding: material flow, joint structure and strength", Journal of achievements in materials and manufacturing, volume.55 ISSUE 2.

[6] H.Bisadi, M. Tour, A. Tavakoli. (2011). "The Influence of Process Parameters on Microstructure and Mechanical Properties of Friction Stir Welded Al 5083 Alloy Lap Joint", American Journal of Materials Science; 1(2): 93-97.

[7] Muna Khethier Abbass, Hassan Hady Abd.(2013). "A Comparison Study of Mechanical Properties between Friction Stir Welding and TIG Welded Joints of Aluminum Alloy (Al 6061-T6)", Eng. \&Tech. Journal, Vol. Part (A), No.14.

[8] Sadiq Aziz Husseina,S. Thirua, R. Izamshaha, Abd Salam Md Tahir.( 2014). "The Joining of Three Dissimilar Metallic Alloys by a SinglePass Friction Stir Welding", Sci. Int. (Lahore), 26 (4), 1569-1574.

[9] Muna K. Abbass, Munthir M., Ruqaya Abdulkadhim. (2016). "Optimization of Friction Stir Welding Process Parameters Dissimilar AA2024-T3 and AA7075-T73 Aluminum Alloys by Using Taguchi Method", Al-Khwarizmi Engineering Journal,Vol. 12, No. 1, P.P. 100- 109.

[10] Esther T. Akinlabi, Member, IAENG and Stephen A. Akinlabi. (2016). "Member, IAENG,Effect of rotational Speed on Joint Integrity of Friction Stir Lap Welded Aluminium", WCE, June 29 - July 1, London, U.K.

[11] Muna K.Abbass and Kareem M. Raheef,"Evaluation of the mechanical properties of friction stir lap welded joints for dissimilar aluminum alloys (AA1100 to AA6061)", 1st International Scientific Conference of Engineering Sciences (ISCES), 2018, pp.192-197. 